\title{
Reference intervals of thyroid hormones during pregnancy in Korea, an iodine-replete area
}

\author{
Hye Jeong Kim ${ }^{1,2},{ }^{*}$, Yoon Young Cho ${ }^{1,3,4}{ }^{*}$, Sun Wook Kim ${ }^{1}$, Tae Hyuk Kim ${ }^{1}$, Hye Won Jang ${ }^{5}$, \\ Soo-Youn Lee ${ }^{6}$, Suk-Joo Choi ${ }^{7}$, Cheong-Rae Roh ${ }^{7}$, Jong-Hwa Kim ${ }^{7}$, Jae Hoon Chung ${ }^{1}$, and Soo-young $\mathrm{Oh}^{7}$
}

\begin{abstract}
'Division of Endocrinology and Metabolism, Department of Medicine, Thyroid Center, Samsung Medical Center, Sungkyunkwan University School of Medicine, Seoul; ${ }^{2}$ Division of Endocrinology and Metabolism, Department of Internal Medicine, Soonchunhyang University Hospital Seoul, Seoul; ${ }^{3}$ Division of Endocrinology and Metabolism, Department of Medicine, ${ }^{4}$ Institute of Health Sciences, Gyeongsang National University School of Medicine, Jinju; ${ }^{5}$ Department of Medical Education, Sungkyunkwan University School of Medicine, Seoul; Departments of ${ }^{6}$ Laboratory Medicine and Genetics and ${ }^{7}$ Obstetrics and Gynecology, Samsung Medical Center, Sungkyunkwan University School of Medicine, Seoul, Korea
\end{abstract}

Received: February 26, 2016

Revised : July 5, 2016

Accepted: July 19, 2016

\section{Correspondence to \\ Soo-young Oh, M.D.}

Department of Obstetrics and Gynecology, Samsung Medical

Center, Sungkyunkwan University School of Medicine, 81 Irwon-ro, Gangnam-gu, Seoul 06351, Korea

Tel: +82-2-3410-3517

Fax: +82-2-3410-0630

E-mail: ohsymd.oh@samsung.com

*These authors contributed equally to this work.
Background/Aims: Maternal thyroid dysfunction has been associated with adverse pregnancy outcomes. The purpose of our study was to establish trimester-specific reference intervals for thyroid hormones in pregnant women in Korea, where iodine intake is more than adequate and to examine pregnancy and perinatal outcomes in their offspring.

Methods: Among 459 healthy pregnant women who were screened, we enrolled 417 subjects who had negative results for thyroid autoantibodies. Serum thyroid stimulating hormone (TSH) and free thyroxine were measured using an immunoradiometric assay. Urine iodine concentration was measured using inductively coupled plasma-mass spectrometry in 275 women. Reference ranges of thyroid hormones were determined according to the guidelines of the National Academy of Clinical Biochemistry. Pregnancy and perinatal outcomes were compared according to maternal thyroid function.

Results: The reference ranges of serum TSH were 0.03 to $4.24 \mathrm{mIU} / \mathrm{L}$ in the first trimester, 0.13 to $4.84 \mathrm{mIU} / \mathrm{L}$ in the second trimester, and 0.30 to $5.57 \mathrm{mIU} / \mathrm{L}$ in the third trimester. Pregnancy and perinatal outcomes did not vary in mothers with subtle changes in thyroid function.

Conclusions: Trimester-specific thyroid hormone reference intervals in Korean pregnant women differ from those of other countries with different iodine nutrition status and ethnicity. The establishment of population-based, reliable trimester-specific reference intervals is critical for the interpretation of thyroid function in pregnant women to avoid unnecessary tests and treatments.

Keywords: Thyroid hormones; Reference intervals; Pregnancy; Iodine; Republic of Korea

\section{INTRODUCTION}

Over the past few decades, the association between mater- nal thyroid dysfunction, thyroid antibodies and adverse effects on pregnancy has been studied. Overt thyroid dysfunction is related with adverse obstetric outcomes 
and needs to be treated in pregnant women $[1,2]$. However, subclinical hypothyroidism during pregnancy has insufficient evidence for risks of obstetric problems $[3,4]$ and the preventive effects of levothyroxine treatment $[5,6]$. Moreover, a recent large prospective cohort study suggested potential harmful effects of levothyroxine therapy on the child neurodevelopmental outcomes in pregnant women with subclinical hypothyroidism [7].

As the diagnosis of subclinical thyroid disease depends upon thyroid function test due to the absence of clinical manifestations, determination of trimester-specific reference intervals for thyroid hormones and thyroid stimulating hormone (TSH) is crucial to avoid over- or under-diagnosis of subclinical hypothyroidism in pregnant women [8]. Thyroid function reference ranges vary among different populations, which might be explained by variation in ethnicity, iodine intake, body size as well as assay methodology [8].

The National Academy of Clinical Biochemistry (NACB) recommends that reference intervals for serum TSH should be established using specimens from normal euthyroid subjects excluding individuals having specific features such as goiter and known thyroid disease [9]. When trimester-specific reference values for $\mathrm{TSH}$ are not available according to region and iodine intake, American Thyroid Association (ATA) management guidelines for thyroid disease during pregnancy recommend the use of their TSH reference values: 0.1 to 2.5 $\mathrm{mIU} / \mathrm{L}$ in the first, 0.2 to $3.0 \mathrm{mIU} / \mathrm{L}$ in the second, and 0.3 to $3.0 \mathrm{mIU} / \mathrm{L}$ in the third trimester [10].

World Health Organization (WHO) recommended epidemiologic criteria for assessing iodine nutrition based on the urine iodine concentration (UIC) in pregnant women [11]. A median UIC of 150 to $249 \mu \mathrm{g} / \mathrm{L}$ is considered as an adequate intake of iodine. A UIC between 250 and $499 \mu \mathrm{g} / \mathrm{L}$ is more-than-adequate, and 500 $\mu \mathrm{g} / \mathrm{L}$ or more is defined as excessive iodine intake. We reported the median UIC of $427.3 \mu \mathrm{g} / \mathrm{L}$ in Korean pregnant women, which is more-than-adequate according to WHO criteria [12].

Recently, the TSH and free thyroxine ( $\left.\mathrm{fT}_{4}\right)$ reference intervals are reported in 465 Korean pregnant women using electrochemiluminescence immunoassay (Roche Diagnostics, Mannheim, Germany) [13]. However, the previous study has limitations in that they did not investigate iodine status and pregnancy outcomes in their population [13].

Here, we aimed to establish trimester-specific reference intervals for TSH and $\mathrm{fT}_{4}$ using immunoradiometric assay (Beckman Coulter, Brea, CA, USA), complying with the NACB guidelines. In addition, we examined pregnancy and perinatal outcomes according to the new TSH reference intervals.

\section{METHODS}

\section{Study population}

From April 2012 to March 2014, healthy pregnant women who visited Samsung Medical Center for routine antenatal checkups were consecutively and prospectively enrolled. Exclusion criteria included women with a visible or palpable diffuse or nodular goiter, a history of thyroid disease or medication usage, positive for thyroid autoantibodies and multifetal gestation. Among a total of 459 women who were screened for thyroid autoantibodies, 42 (9.2\%) were excluded for positive thyroid autoantibodies; thus, a total of 417 subjects were enrolled in this study (Table 1).

\section{Pregnancy and perinatal outcomes}

Pregnancy and perinatal outcomes were available in 371 pairs of mothers and their singleton babies after exclusion of 46 pregnant women who gave birth at outside hospitals. Gestational hypertension was defined as systolic blood pressure $\geq 140 \mathrm{mmHg}$ or diastolic blood pressure $\geq 90 \mathrm{mmHg}$ during pregnancy. Severe preeclampsia was defined as women with hypertension and $\geq 1$ of following conditions; blood pressure $\geq$ $160 / 110 \mathrm{mmHg}$, serum creatinine $>1.1 \mathrm{mg} / \mathrm{dL}$, thrombocytopenia $(<100,000$ platelets $/ \mu \mathrm{L})$, serum transaminase concentration more than twice an upper normal limit, persistent headache or scotomata [14]. Major malformations in infants included anomalies in principal organs, an identifiable syndrome and aneuploidy [15]. Neonatal TSH was checked using a capillary heel stick blood sampling between 3 and 7 days after birth for a routine newborn screening. Informed consent was obtained from all the participants and the Institutional Review Board of Samsung Medical Center approved this study. 
Table 1. Prevalence of thyroid autoantibodies in pregnant women

\begin{tabular}{lcccc}
\hline \multirow{2}{*}{ Thyroid autoantibodies } & & Trimester & Third & Total \\
\cline { 2 - 4 } & First & Second & $9(6.0)$ & $28(6.1)$ \\
$\operatorname{TPO}(+)$ & $12(7.7)$ & $7(4.6)$ & $3(2.0)$ & $20(4.4)$ \\
$\operatorname{Tg}(+)$ & $13(8.4)$ & $4(2.6)$ & 0 & $6(1.3)$ \\
$\operatorname{TPO}(+)$ and $\operatorname{Tg}(+)$ & $5(3.2)$ & $1(0.7)$ & $12(7.9)$ & $42(9.2)$ \\
TPO $(+)$ or $\operatorname{Tg}(+)$ & $20(12.9)$ & $10(6.5)$ & $139(92.1)$ & $417(90.8)$ \\
TPO $(-)$ and $\operatorname{Tg}(-)$ & $135(87.1)$ & $143(93.5)$ & \\
\hline
\end{tabular}

Values are presented as number (\%). Positivity of anti-TPO antibody and anti-Tg antibody was defined as plasma concentrations of $60 \mathrm{IU} / \mathrm{mL}$ or greater. Only subjects without anti-TPO antibody and anti-Tg antibody were included in the analysis of normal thyroid hormone reference intervals in pregnant women.

TPO, thyroid peroxidase; $\mathrm{Tg}$, thyroglobulin.

\section{Laboratory tests}

Maternal blood samples were obtained at the time of enrollment and stored at $-80^{\circ} \mathrm{C}$. Serum TSH, $\mathrm{fT}_{4}$ was measured using an immunoradiometric assay. The intraand interassay coefficients of variation were $\leq 3.7 \%$ and 8.6\% for $\mathrm{TSH}$, and $\leq 10.29 \%$ and $7.58 \%$ for $\mathrm{fT}_{4}$, respectively. Anti-thyroid peroxidase (anti-TPO) antibody was determined using a radioimmunoassay kit (BRAHMS AG, Hennigsdorf, Germany) and anti-thyroglobulin (anti-Tg) antibody was measured using an anti-Tg RIA kit (BRAHMS AG). Anti-TPO antibody and anti-Tg antibody less than $60 \mathrm{U} / \mathrm{mL}$ were considered negative according to the manufacturer's instructions. All samples were measured in triplicate.

Among 417 women, urine samples were obtained from 275 subjects at the time of blood sampling. Urinary iodine was measured by inductively coupled plasma-mass spectrometry using an Agilent 7500 series instrument (Agilent Technologies Inc., Tokyo, Japan) as described in a previous study [16].

\section{Statistical analysis}

SPSS version 18 (SPSS Inc., Chicago, IL, USA) was used for statistical analysis. Descriptive characteristics were tabulated for baseline characteristics using one-way analysis of variance for parametric statistics and the Kruskall-Wallis test for non-parametric statistics, if appropriate. Percentile values for TSH and $\mathrm{fT}_{4}$ were presented with 2.5 th, 5th, 25th, 50th, 75th, 95th, and 97.5th percentiles. Reference ranges for $\mathrm{TSH}$ and $\mathrm{fT}_{4}$ in each trimester were defined as the range between 2.5th and 97.5th percentiles according to NACB recommenda- tions. Women with TSH above the 97.5th percentile but normal $\mathrm{fT}_{4}$ based on reference values determined from our population were regarded as having subclinical hypothyroidism.

\section{RESULTS}

\section{Baseline characteristics}

A total of 417 healthy pregnant women were eligible for analysis; 135 women in the first trimester, 143 in the second trimester and 139 in the third trimester. The baseline demographics are presented in Table 2. The mean age at study enrollment was 33 years. Mean weight was $60 \mathrm{~kg}$ and as expected, maternal body weight increased with advanced gestational age (GA; $p<0.001)$. Median TSH was 1.32, 1.62, and 1.59 mIU/L in each trimester (Fig. 1). Median $\mathrm{fT}_{4}$ was 1.14, 0.91 , and $0.88 \mathrm{ng} / \mathrm{dL}$, respectively $(p<0.001)$. Median UIC of all subjects was $429 \mu \mathrm{g} / \mathrm{L}$ and no difference was observed among each trimester.

\section{Reference intervals of $\mathrm{TSH}$ and $\mathrm{fT}_{4}$ in each trimester} Percentile values of TSH and $\mathrm{fT}_{4}$ are presented as 2.5th, 5th, 25th, 50th, 75th, 95th, and 97.5th percentiles in each trimester (Table 3). Reference intervals of TSH were defined as the range between the 2.5th and 97.5th percentiles; TSH between 0.03 to $4.24 \mathrm{mIU} / \mathrm{L}$ in the first trimester, 0.13 to $4.84 \mathrm{mIU} / \mathrm{L}$ in the second trimester, and 0.30 to $5.57 \mathrm{mIU} / \mathrm{L}$ in the third trimester. For $\mathrm{fT}_{4}$, reference intervals were between 0.84 to $1.43 \mathrm{ng} / \mathrm{dL}$ in the first trimester, 0.68 to $1.21 \mathrm{ng} / \mathrm{dL}$ in the second trimester, and 0.67 to $1.13 \mathrm{ng} / \mathrm{dL}$ in the third trimester. 
Table 2. Baseline characteristics of study subjects $(n=417)$

\begin{tabular}{|c|c|c|c|c|}
\hline \multirow{2}{*}{ Variable } & \multicolumn{3}{|c|}{ Trimester } & \multirow{2}{*}{$p$ value $^{\mathrm{a}}$} \\
\hline & First & Second & Third & \\
\hline No. of subjects & 135 & 143 & 139 & \\
\hline Age, yr & $32 \pm 3$ & $33 \pm 4$ & $33 \pm 3$ & 0.020 \\
\hline Weight, kg & $55 \pm 8$ & $60 \pm 7$ & $65 \pm 8$ & $<0.001$ \\
\hline TSH, mIU/L & $1.32(0.01-9.43)$ & $1.62(0.01-7.40)$ & $1.59(0.15-7.54)$ & 0.280 \\
\hline $\mathrm{fT}_{4}, \mathrm{ng} / \mathrm{dL}$ & $1.14(0.77-2.22)$ & $0.91(0.64-1.64)$ & $0.88(0.54-1.20)$ & $<0.001$ \\
\hline $\mathrm{UIC}, \mu \mathrm{g} / \mathrm{L}^{\mathrm{b}}$ & $439(20-5,020)$ & $397(29-10,192)$ & $451(19-5,431)$ & 0.480 \\
\hline
\end{tabular}

Values are presented as mean \pm SD or median (range).

TSH, thyroid stimulating hormone; $\mathrm{fT}_{4}$, free thyroxine; UIC, urinary iodine concentration.

${ }^{a}$ One-way analysis of variance or Kruskall-Wallis test was used for the comparison of variables from each trimester.

${ }^{b}$ Urine samples were collected from 275 subjects: 65 samples in the first trimester, 108 in the second trimester, and 102 in the third trimester.

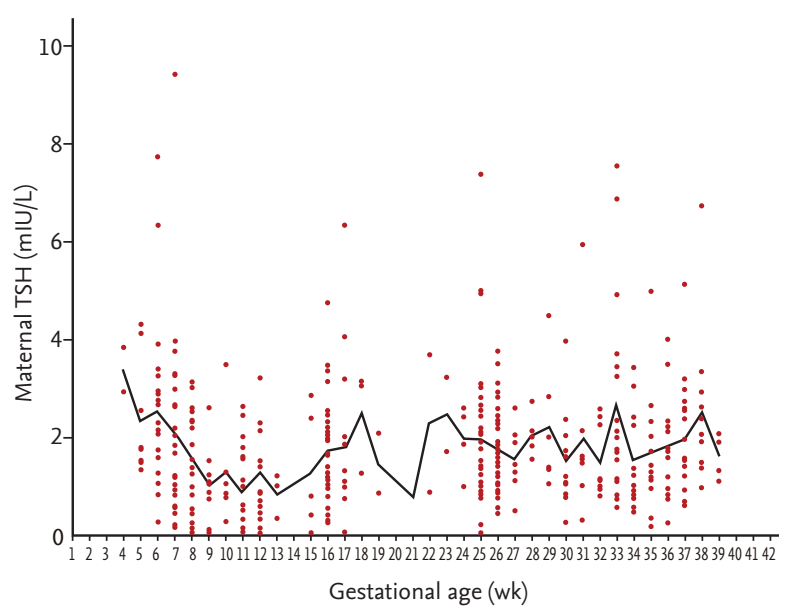

Figure 1. Changes in maternal serum thyroid stimulating hormone (TSH) according to gestational age. Red dots indicate maternal serum TSH concentrations measured in each pregnant woman and solid line indicates the median level of serum TSH in each gestational age.

Using the ATA guidelines for pregnant women in our population, 34 women $(25.2 \%)$ in the first trimester, 18 $(12.6 \%)$ in the second trimester, and $18(12.9 \%)$ in the third trimester met criteria for subclinical hypothyroidism (Table 3).

\section{Pregnancy and perinatal outcomes according to maternal thyroid function}

Pregnancy and perinatal outcomes for 371 pairs of mothers and babies (including fetal death) were presented in Table 4. Maternal thyroid function was determined by criteria established in our population. Among 371 moth- ers, 344 mothers (92.7\%) showed euthyroid status, 11 (3\%) with subclinical hypothyroidism, 11 (3\%) with subclinical hyperthyroidism, and five (1.3\%) with isolated hypothyroxemia. There was no difference in pregnancy and perinatal outcomes among mothers with different thyroid functional status. The median neonatal TSH was higher in babies from mothers with subclinical hypothyroidism and isolated hypothyroxemia than those from mothers with euthyroid and subclinical hyperthyroidism, but the difference was not significant. A male baby from subclinical hypothyroid mother entered intensive care unit for fetal asphyxia. He was born with small for GA $(2,040 \mathrm{~g})$ at GA $37+2$ (week + day). His mother was elderly pregnant women (42-year-old) without any pregnant complication. Her serum TSH was $9.43 \mathrm{mIU} / \mathrm{L}$ at GA $7+2$, but spontaneously decreased to $2.11 \mathrm{mIU} / \mathrm{L}$ at GA $11+2$ and $2.80 \mathrm{mIU} / \mathrm{L}$ at $21+4$ without medication.

\section{DISCUSSION}

This prospective, observational study suggested that trimester-specific reference intervals of TSH in pregnant Korean women were different from those in other countries with different levels of iodine intake. We strictly followed the NACB guidelines to set up normal reference intervals of TSH among pregnant Korean women in this study. The normal reference intervals obtained from this study (0.03 to $4.24 \mathrm{mIU} / \mathrm{L}$ for the first, 0.13 to $4.84 \mathrm{mIU} / \mathrm{L}$ for the second, and 0.30 to $5.57 \mathrm{mIU} / \mathrm{L}$ for the third trimester) have a wider range than those recom- 
Table 3. Trimester-specific percentile values of TSH and $\mathrm{fT}_{4}$

\begin{tabular}{|c|c|c|c|c|c|c|c|c|c|c|}
\hline \multirow[t]{2}{*}{ Trimester } & \multirow{2}{*}{$\begin{array}{c}\text { No. of } \\
\text { subjects }\end{array}$} & \multicolumn{7}{|c|}{ Percentile values } & \multicolumn{2}{|c|}{$\begin{array}{l}\text { Prevalence of subclinical hypothy } \\
\text { roidism based on two criteria, } \mathrm{n}(\%)\end{array}$} \\
\hline & & $2.5^{\text {th }}$ & $5^{\text {th }}$ & $25^{\text {th }}$ & 5oth & $75^{\text {th }}$ & $95^{\text {th }}$ & 97.5 th & This study ${ }^{\mathrm{a}}$ & ATA guidelines \\
\hline \multicolumn{11}{|c|}{ TSH, mIU/L } \\
\hline First & 135 & 0.03 & 0.08 & 0.65 & 1.32 & 2.48 & 3.92 & 4.24 & $4(3.0)$ & $34(25.2)$ \\
\hline Second & 143 & 0.13 & 0.39 & 0.98 & 1.62 & 2.34 & 3.67 & 4.84 & $4(2.8)$ & $18(12.6)$ \\
\hline Third & 139 & 0.30 & 0.56 & 1.10 & 1.59 & 2.35 & $4 \cdot 52$ & $5 \cdot 57$ & $4(2.9)$ & $18(12.9)$ \\
\hline \multicolumn{11}{|l|}{$\mathrm{fT}_{4}, \mathrm{ng} / \mathrm{dL}$} \\
\hline First & 135 & 0.84 & 0.92 & 1.05 & 1.14 & 1.22 & 1.40 & 1.43 & - & - \\
\hline Second & 143 & 0.68 & 0.72 & 0.81 & 0.91 & 0.99 & 1.13 & 1.21 & - & - \\
\hline Third & 139 & 0.67 & 0.69 & 0.79 & 0.88 & 0.95 & 1.08 & 1.13 & - & - \\
\hline
\end{tabular}

TSH, thyroid stimulating hormone; $\mathrm{fT}_{4}$, free thyroxine, ATA; American Thyroid Association.

${ }^{a}$ Reference values for TSH in pregnant women are defined as ranging from the 2.5th to 97.5th percentile: 0.03 to $4.24 \mathrm{mIU} / \mathrm{L}$ in the first trimester, 0.13 to $4.84 \mathrm{mIU} / \mathrm{L}$ in the second trimester, and 0.3 to $5.57 \mathrm{mIU} / \mathrm{L}$ in the third trimester.

${ }^{\mathrm{b}}$ Current guidelines from the ATA recommend maternal TSH between 0.1 to $2.5 \mathrm{mIU} / \mathrm{L}$ in the first trimester, 0.2 to $3.0 \mathrm{mIU} / \mathrm{L}$ in the second trimester, and 0.3 to $3.0 \mathrm{mIU} / \mathrm{L}$ in the third trimester.

mended by the ATA guidelines. In addition, we evaluated neonatal outcomes according to maternal thyroid function.

Our data showed that among pregnant women without known thyroid disease in Korea, $6.1 \%$ of women tested positive for TPO antibody and $4.4 \%$ of women tested positive for $\mathrm{Tg}$ antibody. These prevalence rates are lower than those of previous studies that reported prevalence rates for TPO antibody of $10.4 \%$ to $19.8 \%$ and $\mathrm{Tg}$ antibody of $5.5 \%$ to $15.7 \%[17,18]$. This may be explained by the existence of ethnic differences and the enrollment of women without apparent goiters and without a history of thyroid disease in this study.

After exclusion of women positive for thyroid autoantibodies, the upper reference limit of trimester-specific TSH reference values established in this study was higher than those of other studies from Switzerland [17], the United States [19], and Spain [20], which reported upper TSH limits of 2.83 to $2.90 \mathrm{mIU} / \mathrm{L}$ in the first, 2.78 to 2.99 $\mathrm{mIU} / \mathrm{L}$ in the second, and 2.64 to $3.56 \mathrm{mIU} / \mathrm{L}$ in the third trimester $[17,19,20]$. On the other hand, the reference intervals in this study were comparable to those reported in India [21] and China [22]. Owing to substantial variation of TSH reference intervals among different populations, each institution is recommended to set their own trimester-, assay-specific reference ranges for pregnant women $[8,10]$.
Recently, Moon et al. [13] reported reference intervals (2.5th to 97.5th percentile) for TSH and $\mathrm{fT}_{4}$ in 465 Korean pregnant women: for TSH 0.01 to $4.10 \mathrm{mIU} / \mathrm{L}$ (first trimester), 0.01 to $4.26 \mathrm{mIU} / \mathrm{L}$ (second trimester), and 0.15 to $4.57 \mathrm{mIU} / \mathrm{L}$ (third trimester); and for $\mathrm{fT}_{4}, 0.83$ to $1.65 \mathrm{ng} / \mathrm{dL}$ (first trimester), 0.71 to $1.22 \mathrm{ng} / \mathrm{dL}$ (second trimester), and 0.65 to $1.13 \mathrm{ng} / \mathrm{dL}$ (third trimester). We confirmed wider ranges of TSH and $\mathrm{fT}_{4}$ reference intervals in Korean pregnant women using different assay (Beckman Coulter) and provided additional information on iodine status which is one of the factors affecting maternal thyroid function.

Korea is an iodine-replete country and the median UIC of $429 \mu \mathrm{g} / \mathrm{L}$ in healthy pregnant women who had no evidence of thyroid disease, exceeding those of pregnant women living in nearby Asian countries [18,23]. Although adequate iodine intake is essential for normal fetal brain development and the synthesis of maternal thyroid hormones, excessive iodine status is related to maternal subclinical hypothyroidism [18]. Sang et al. [18] reported the higher prevalence of subclinical hypothyroidism (20\%) in pregnant women with excessive iodine intake compared to those with adequate iodine intake (2.3\%), but the rates of overt hypothyroidism were simi$\operatorname{lar}(0.5 \%$ vs. $0 \%)$.

According to the reference ranges provided by current ATA guidelines, the prevalence of subclinical hypothy- 
Table 4. Pregnancy and perinatal outcomes based on maternal thyroid function $(n=371)^{a}$

\begin{tabular}{|c|c|c|c|c|}
\hline \multirow[b]{2}{*}{ Variable } & \multicolumn{4}{|c|}{ Criteria from this study ${ }^{\mathrm{b}}$} \\
\hline & $\begin{array}{c}\text { Subclinical } \\
\text { hypothyroidism } \\
(\mathrm{n}=11,3 \%)\end{array}$ & $\begin{array}{c}\text { Euthyroid } \\
(\mathrm{n}=344,92.7 \%)\end{array}$ & $\begin{array}{c}\text { Subclinical } \\
\text { hyperthyroidism } \\
(\mathrm{n}=11,3 \%)\end{array}$ & $\begin{array}{c}\text { Isolated } \\
\text { hypothyroxemia } \\
(\mathrm{n}=5,1.3 \%)\end{array}$ \\
\hline \multicolumn{5}{|l|}{ Maternal clinical characteristics } \\
\hline Age, yr & $35 \pm 2$ & $33 \pm 3$ & $32 \pm 4$ & $38 \pm 4$ \\
\hline TSH, mIU/L & $6.34(4.30-9.43)$ & $1.57(0.04-5.12)$ & $0.02(0.01-0.28)$ & $2.10(1.22-3.99)$ \\
\hline $\mathrm{fT}_{4}, \mathrm{ng} / \mathrm{dL}$ & $0.90(0.7-1.18)$ & $0.94(0.67-1.40)$ & $1.13(0.89-1.67)$ & $0.64(0.63-0.67)$ \\
\hline $\mathrm{UIC}, \mu \mathrm{g} / \mathrm{L}$ & $929(242-2,617)$ & $437(19-10,192)$ & $510(180-2,061)$ & NA (38-459) \\
\hline $\begin{array}{l}\text { Trimester at enrollment, } \\
\text { first/second/third }\end{array}$ & $4 / 4 / 3$ & $101 / 117 / 126$ & $4 / 4 / 3$ & $0 / 3 / 2$ \\
\hline \multicolumn{5}{|l|}{ Pregnancy outcome } \\
\hline Hypertension & 0 & $5(1.5)$ & 0 & 0 \\
\hline Gestational & o & $1(0.3)$ & o & $\mathrm{O}$ \\
\hline Severe preeclampsia & 0 & $4(1.2)$ & 0 & 0 \\
\hline Gestational diabetes & o & $6(1.7)$ & o & 0 \\
\hline Placental abruption & 0 & $4(1.2)$ & 0 & 0 \\
\hline $\begin{array}{l}\text { Gestation at delivery, } \\
\text { median wk + day }\end{array}$ & $39+2$ & $39+3$ & $40+2$ & $38+3$ \\
\hline 34 Weeks or less & 0 & $3(0.9)$ & 0 & 0 \\
\hline 37 Weeks or less & o & $13(3.8)$ & $1(9.1)$ & 0 \\
\hline Cesarean delivery & $2(18.2)$ & $80(23.2)$ & 0 & $1(20)$ \\
\hline Repeat & 0 & $29(8.4)$ & o & 0 \\
\hline Primary & $2(18.2)$ & $51(14.8)$ & 0 & 0 \\
\hline Dystocia & $1(9.1)$ & $23(6.7)$ & o & 0 \\
\hline Fetal distress & $1(9.1)$ & $17(4.9)$ & 0 & $1(20)$ \\
\hline Other & o & $11(3.2)$ & 0 & 0 \\
\hline \multicolumn{5}{|l|}{ Perinatal outcome } \\
\hline No. of live-born babies & $10(90.9)$ & $341(99.1)$ & $11(100)$ & $5(100)$ \\
\hline Fetal death ${ }^{\mathrm{c}}$ & $1(9.1)^{c}$ & $3(0.9)^{c}$ & 0 & 0 \\
\hline Birth weight, g & $3,395(2,040-3,570)$ & $3,180(690-4,230)$ & $3,350(2,760-3,550)$ & $3,500(2,930-3,670)$ \\
\hline$\leq 1,000$ & 0 & $1(0.3)$ & 0 & 0 \\
\hline$\leq 1,500$ & O & o & O & O \\
\hline$\leq 2,500$ & $1(9.1)^{d}$ & $16(4 \cdot 7)$ & 0 & o \\
\hline Admission to intensive care unit & $1(9.1)^{\mathrm{d}}$ & $11(3.2)$ & o & 0 \\
\hline Apgar score $\leq 3$ at 5 minutes & $1(9.1)^{\mathrm{d}}$ & o & o & 0 \\
\hline Major malformation & 0 & $10(2.9)$ & o & o \\
\hline Neonatal death & 0 & $1(0.3)^{\mathrm{e}}$ & 0 & 0 \\
\hline Neonatal TSH, mIU/L ${ }^{\mathrm{f}}$ & $3.13(2.29-6.81)$ & $3.00(1.56-4.41)$ & $2.69(1.68-3.66)$ & $3.32(1.34-7.18)$ \\
\hline
\end{tabular}

Values are presented as mean $\pm \mathrm{SD}$, median (range), or number (\%).

TSH, thyroid stimulating hormone; $\mathrm{fT}_{4}$, free thyroxine; UIC, urinary iodine concentration; NA, not available.

${ }^{a}$ After exclusion of 46 pregnant women who had given birth to their babies at outside hospitals, a total of 371 pairs of mothers and singleton babies (including fetal death) were analyzed for pregnancy and perinatal outcomes.

${ }^{\mathrm{b}}$ Reference values for TSH in pregnant women are defined as ranging from the 2.5th to 97.5th percentile: 0.03 to $4.24 \mathrm{mIU} / \mathrm{L}$ in the first trimester, 0.13 to $4.84 \mathrm{mIU} / \mathrm{L}$ in the second trimester, and 0.3 to $5.57 \mathrm{mIU} / \mathrm{L}$ in the third trimester; reference intervals 


\section{Table 4. Continued.}

for $\mathrm{fT}_{4}$ are defined as ranging from the 2.5 th to 97.5 th percentile: 0.84 to $1.43 \mathrm{ng} / \mathrm{dL}$ in the first trimester, 0.68 to $1.21 \mathrm{ng} / \mathrm{dL}$ in the second trimester, and 0.67 to $1.13 \mathrm{ng} / \mathrm{dL}$ in the third trimester.

${ }^{c}$ Fetal death is defined as spontaneous intrauterine death of a fetus at any time during pregnancy. One case from subclinical hypothyroid mother occurred at gestational age (GA) $11+2$ and three cases from euthyroid mothers occurred at GA $14+5$, GA $16+4$, and GA $21+0$, respectively.

${ }^{\mathrm{d}}$ A male baby was born at GA $37+2$ with small for GA $(2,040 \mathrm{~g})$. During delivery, emergent cesarean section was performed due to fetal distress and the Apgar score was 1 point at 1 minute and 2 point at 5 minutes. The baby entered intensive care unit for fetal asphyxia.

${ }^{\mathrm{e}}$ A female baby with total anomalous pulmonary venous return (TAPVR) undergone operation immediate after birth to correct TAPVR; however, she expired due to intractable pulmonary hypertension in 10 weeks after birth.

${ }^{\mathrm{f}}$ Neonatal TSH was checked using a capillary heel stick blood sampling between 3 and 7 days after birth for a routine newborn screening.

roidism was $25.2 \%$ in the first trimester, $12.6 \%$ in the second trimester, and $12.9 \%$ in the third trimester in the present study. That is, about one quarter of pregnant women would be possible candidates for levothyroxine treatment in the first trimester. Li et al. [22] drew similar conclusions in Chinese pregnant women of a high prevalence of subclinical hypothyroidism (27.8\%) based on a fixed upper limit of $2.5 \mathrm{mIU} / \mathrm{L}$ in early pregnancy. Interestingly, Korevaar et al. [7] reported that both low and high maternal $\mathrm{fT}_{4}$ levels during pregnancy resulted in lower child IQ (a median of 6.o years of age) and lower gray matter and cortex volume, warning the potential adverse effects of preventive levothyroxine therapy in subclinical hypothyroid mothers.

Maternal subclinical hypothyroidism has been described as a factor for pregnancy loss, premature delivery, low birth weight (LBW) and hypertensive disorder, but results are inconclusive $[2,3,8]$. A recent meta-analysis concluded that subclinical hypothyroidism and isolated hypothyroxemia did not increase the risk of preterm birth [2]. A study using the National Birth Registration (NBR) data reported that a prevalence of preterm birth (<37 weeks gestation) between $3.4 \%$ to $5.9 \%$ and LBW (< $2,500 \mathrm{~g}$ ) between $3.2 \%$ to $5.2 \%$ in Korea (2004 to 2008) [24], and our results are comparable with the prevalence from NBR database. One baby with LBW and low Apgar score who admitted to intensive care unit was born from a 42-year-old mother who showed subclinical hypothyroidism (TSH of $9.43 \mathrm{mIU} / \mathrm{L}$ ) at $\mathrm{GA} 7+2$. In general, serum TSH levels decrease from the 8th weeks throughout the first half of pregnancy [22], and her TSH was normalized without any intervention. Thus, it is expected that the perinatal outcome might be derived from the elder- ly gravida rather than maternal thyroid dysfunction. We reported no difference in pregnancy and perinatal outcomes between subclinical hypothyroid and euthyroid mothers and their babies using TSH reference intervals determined in our population, although the number of women with subtle changes of thyroid function was too small to compare these outcomes. Excessive iodine intake is related to the subclinical hypothyroidism, but data is limited which subclinical thyroid diseases in mothers affect the short and long-term outcomes in offspring, especially in iodine-replete area. Therefore, the relationship between minor variation in maternal thyroid function using population-based reference intervals and offspring's outcomes such as intellectual, behavioral development and thyroid function needs to be validated in larger cohort studies.

There are some limitations to this study. First, this study only used one kit for serum TSH and $\mathrm{fT}_{4}$ measurements and was not tested using different kits. Thus, these reference intervals need to be used with caution when different kits are used. Fortunately, the measurement of serum TSH is better internationally standardized compared to other blood tests for thyroid function including $\mathrm{fT}_{4}$. Second, this study was conducted at a tertiary referral hospital and not in a primary care hospital setting. However, the Obstetric Department of our institution functions not only as a tertiary referral hospital, but also as a primary care center for pregnant women in this area. This is because the hospital is located in a populated area, where $44 \%$ of entire population resides, but only a few delivery hospitals are nearby due to poor reimbursement for childbirth from the National Health Insurance System. Considering that the percentages of 
preterm birth, LBW and congenital malformation are similar to the prevalence reported from NBR database and multicenter data (birth defect of $2.7 \%$ in this study vs. $1.8 \%$ in multicenter data) [25], we are confident that the participants in this study are not deviated for highrisk pregnant women, but they seem not to be representative of average pregnant women in Korea due to limited number of subjects. Third, maternal TSH concentrations in each trimester were not measured serially in the same pregnant women. However, we think this does not affect the study aim which is to set the reference intervals of serum TSH level in each trimester during pregnancy in Korea. Forth, UIC was measured in limited number of subjects and fetal outcome was not identified in babies born at outside hospital. Fifth, we did not study the long-term neuropsychological development of children born from mothers with different levels of serum TSH. We identified no adverse effect on perinatal outcome of subclinical hypothyroid mothers, but it does not guarantee the long-term safety for their offspring; thus, population-based studies are warranted to clarify this issue.

In conclusion, this study provides trimester-specific reference intervals of thyroid hormones in pregnant Korean women that differed from those of pregnant women in other countries with different ethnicity and iodine nutrition. These findings will reduce the number of pregnant women who may be classified as having subclinical hypothyroidism and are subjected to unnecessary levothyroxine treatment. In addition, education about adequate iodine intake during pregnancy to prevent both inadequate and excessive iodine intake must be emphasized. Further investigations on the association between thyroid hormones and clinical outcomes are needed.

\section{KEY MESSAGE}

1. Korean pregnant women have wider ranges of thyroid hormone reference intervals and pregnancy outcomes did not vary in mothers with subtle changes in thyroid function.

2. These findings will reduce the number of pregnant women who may be classified as having subclinical hypothyroidism and are subjected to unnecessary levothyroxine treatment.

\section{Conflict of interest}

No potential conflict of interest relevant to this article was reported.

\section{Acknowledgments}

This study was supported by a Samsung Medical Center grant (\#PHO 1125465).

\section{REFERENCES}

1. Allan WC, Haddow JE, Palomaki GE, et al. Maternal thyroid deficiency and pregnancy complications: implications for population screening. J Med Screen 2000;7:127130.

2. Sheehan PM, Nankervis A, Araujo Junior E, Da Silva Costa F. Maternal thyroid disease and preterm birth: systematic review and meta-analysis. J Clin Endocrinol Metab 2015;100:4325-4331.

3. Casey BM, Dashe JS, Wells CE, et al. Subclinical hypothyroidism and pregnancy outcomes. Obstet Gynecol 2005;105:239-245.

4. Cleary-Goldman J, Malone FD, Lambert-Messerlian G, et al. Maternal thyroid hypofunction and pregnancy outcome. Obstet Gynecol 2008;112:85-92.

5. Negro R, Schwartz A, Gismondi R, Tinelli A, Mangieri T, Stagnaro-Green A. Universal screening versus case finding for detection and treatment of thyroid hormonal dysfunction during pregnancy. J Clin Endocrinol Metab 2010;95:1699-1707.

6. Lazarus JH, Bestwick JP, Channon S, et al. Antenatal thyroid screening and childhood cognitive function. $\mathrm{N}$ Engl J Med 2012;366:493-501.

7. Korevaar TI, Muetzel R, Medici M, et al. Association of maternal thyroid function during early pregnancy with offspring IQ and brain morphology in childhood: a population-based prospective cohort study. Lancet Diabetes Endocrinol 2016;4:35-43.

8. Medici M, Korevaar TI, Visser WE, Visser TJ, Peeters RP. Thyroid function in pregnancy: what is normal? Clin Chem 2015;61:704-713.

9. Baloch Z, Carayon P, Conte-Devolx B, et al. Laboratory medicine practiceguidelines: laboratory support for the diagnosis and monitoring of thyroid disease. Thyroid 2003;13:3-126.

10. Stagnaro-Green A, Abalovich M, Alexander E, et al. Guide- 
lines of the American Thyroid Association for the diagnosis and management of thyroid disease during pregnancy and postpartum. Thyroid 2011;21:1081-1125.

11. International Council for Control of Iodine Deficiency Disorders; UNICEF; World Health Organization. Assessment of Iodine Deficiency Disorders and Monitoring Their Elimination: A Guide for Programme Managers. 3rd ed. Geneva: World Health Organization, 2007.

12. Cho YY, Kim HJ, Oh SY, et al. Iodine status in healthy pregnant women in Korea: a first report. Eur J Nutr 2016:55:469-475.

13. Moon HW, Chung HJ, Park CM, Hur M, Yun YM. Establishment of trimester-specific reference intervals for thyroid hormones in Korean pregnant women. Ann Lab Med 2015;35:198-204.

14. American College of Obstetricians and Gynecologists; Task Force on Hypertension in Pregnancy. Hypertension in pregnancy: report of the American College of Obstetricians and Gynecologists' Task Force on Hypertension in Pregnancy. Obstet Gynecol 2013;122:1122-1131.

15. Koster EL, McIntire DD, Leveno KJ. Recurrence of mild malformations and dysplasias. Obstet Gynecol 2003;102:363366.

16. Lee JH, Ji OJ, Song MJ, et al. Determination of urinary iodine concentration by inductively coupled plasma-mass spectrometry in thyroid cancer patients on low-iodine diet. Korean J Lab Med 2010;30:351-356.

17. Stricker R, Echenard M, Eberhart R, et al. Evaluation of maternal thyroid function during pregnancy: the importance of using gestational age-specific reference intervals. Eur J Endocrinol 2007;157:509-514.
18. Sang Z, Wei W, Zhao N, et al. Thyroid dysfunction during late gestation is associated with excessive iodine intake in pregnant women. J Clin Endocrinol Metab 2012;97: E1363-E1369.

19. Soldin OP, Soldin D, Sastoque M. Gestation-specific thyroxine and thyroid stimulating hormone levels in the United States and worldwide. Ther Drug Monit 2007;29:553-559.

20. Bocos-Terraz JP, Izquierdo-Alvarez S, Bancalero-Flores JL, et al. Thyroid hormones according to gestational age in pregnant Spanish women. BMC Res Notes 2009;2:237.

21. Marwaha RK, Chopra S, Gopalakrishnan S, et al. Establishment of reference range for thyroid hormones in normal pregnant Indian women. BJOG 2008;115:602-606.

22. Li C, Shan Z, Mao J, et al. Assessment of thyroid function during first-trimester pregnancy: what is the rational upper limit of serum TSH during the first trimester in Chinese pregnant women? J Clin Endocrinol Metab 2014;99:73-79.

23. Fuse Y, Ohashi T, Yamaguchi S, Yamaguchi M, Shishiba $\mathrm{Y}$, Irie M. Iodine status of pregnant and postpartum Japanese women: effect of iodine intake on maternal and neonatal thyroid function in an iodine-sufficient area. J Clin Endocrinol Metab 2011;96:3846-3854.

24. Lee JY, Park JS, Jun JK, Shin SH, Ko YJ, Park SM. The associations between bridal pregnancy and obstetric outcomes among live births in Korea: population-based study. PLoS One 2014;9:e103178.

25. Yang JH, Kim YJ, Chung JH, et al. A multi-center study for birth defect monitoring systems in Korea. J Korean Med Sci 2004;19:509-513. 